\title{
GRUPOS EMPRESARIALES E INVERSION DE CAPITAL EN VIZCAYA, 1886-1913
}

JESUS M.* VALDALISO GAGO Universidad del País Vasco

Esta investigación se basa en una explotación sistemática de una fuente hasta ahora sólo utilizada para reconstruir indicadores económicos de larga duración, los Libros de Sociedades del Registro Mercantil. Pero, además, es susceptible de una explotación mucho más intensiva que consistiría, básicamente, en la reconstrucción de los grupos empresariales y de su dinámica inversora, mediante la recogida de los nombres de los inversores que aparecen en las Escrituras de Constitución de cada Sociedad.

Esto es lo que hemos hecho para Vizcaya en un periodo concreto, 1886 . 1913, período que supone para esta región una consolidación de su proceso de industrialización. Así, hemos esbozado un análisis de los principales grupos empresariales, cuyo ritmo de inversiones es un fiel exponente de la estrategia desarrollada en cada sector (minería, navieras, etc.). Junto a ello, la obtención de amplios listados de inversores y la posibilidad de comprobar las relaciones intersectoriales entre los mismos nos ha llevado a contrastar los resultados de la investigación con la teoría tradicional de la industrialización de Vizcaya, que hace de la minería la fuente esencial de capitales que, en manos de un reducido grupo de inversores mineros, fueron luego reinvertidos en la industria.

Las conclusiones finales a la luz de nuestros datos son claras: la minería como tal y los inversores mineros desempeñaron un papel no despreciable en la industrialización de Vizcaya. Pero sus inversiones preferentes se centraron no en la industria y los servicios, sino en minería fuera de Vizcaya. El carácter supuestamente decisivo que se le ha dado a la minería como motor inicial de la revolución industrial en esta provincia debe ser, pues, matizado, y los aportes de la minería valorados en sus justos términos. 


\section{INTRODUCCION *}

La etapa histórica de fines del siglo xix y principios del $\mathbf{x x}$ supuso para Vizcaya la consolidación de su proceso de industrialización. Tradicionalmente, y siguiendo la opinión de mineros de aquella época, se ha atribuido a la exportación de mineral de hierro vizcaíno un protagonismo fundamental de cara al inicio y desarrollo de la industrialización de la provincia ${ }^{1}$. Sólo en los últimos años nuevas investigaciones basadas en un estudio exhaustivo de las fuentes han empezado a cuestionar dicha interpretación, matizando el carácter supuestamente decisivo que la minería tuvo para el crecimiento económico de Vizcaya ${ }^{2}$.

Esta investigación pretende contrastar la llamada teoría tradicional de la industrialización vizcaína con los resultados obtenidos de la explotación de una fuente hasta ahora no utilizada, los Libros de Sociedades del Registro Mercantil de Vizcaya ${ }^{3}$. Nuestro estudio se ha basado en listados de inversores confeccionados tras la recolección, en fichas particularizadas para cada Sociedad, de los nombres de sus socios fundadores. Debido a la magnitud de la tarea -entre 1886 y 1913 se crean, en Vizcaya, 1.830 Sociedades Mercantiles ${ }^{4}$ - la recolección no ha sido completa. Sólo hemos seleccionado las Sociedades más importantes, atendiendo al criterio del volumen de su capital social. Así, el número de Sociedades recogidas supone el 30 por 100 del total de las constituidas en Vizcaya durante ese período, cifra que aumenta hasta un 46 por 100 si sólo tenemos en cuenta a los sectores fundamentales de inversión ${ }^{5}$. Estos porcentajes, significativos, lo son aún más si tenemos en cuenta el capital que representan: más del 90 por 100 del capital total de las Sociedades constituidas en Vizcaya entre 1886 y 1913.

Debido a que no siempre aparece el capital suscrito por cada socio, la

* Debo agradecer a Emiliano Fernández de Pinedo y a J. L. Hernández Marco sus útiles comentarios sobre esta investigación. Asimismo, para la recopilación de las fichas de inversores he contado con la inestimable ayuda de M." Eugenia González Ugarte. Naturalmente, los errores y omisiones son todos de mi responsabilidad.

1 Sobre todo de Lazúrtegui (1907). Autores como Lequerica (1956) o, más recientemente, González Portilla (1981) han sostenido esta interpretación.

${ }^{2}$ Por citar algunas: Fernández de Pinedo (1983), (1985 a) y (1985 b); Escudero (1985) (1986).

${ }^{3}$ Fundamentalmente, este artículo es uno de los capítulos de nuestra tesis de licenciatura: Valdaliso (1986), en la que hemos proporcionado las series de número y capital de las Sociedades Mercantiles constituidas en Vizcaya desde 1886 hasta 1975.

4 Valdaliso (1986), p. 170.

s Que son ocho: metalúrgicas y similares, negocios mineros y derivados, navieras, construcción de obras y similares, productos químicos, negocios eléctricos, compañías ferroviarias y banca y seguros. Sobre esta clasificación sectorial, véase Valdaliso (1986), pp. 13-14. Los porcentajes de los datos recogidos por sectores pueden verse en Valdaliso (1986), p. 115. 
importancia de un inversor en un sector u otro habrá que medirla por su presencia en el mismo, en función del número de veces que aparece en las nuevas Sociedades creadas. Aunque somos conscientes de que este supuesto entraña un cierto riesgo, creemos que los listados de inversores resultantes pueden reflejar nítidamente la conducta empresarial y las decisiones de inversión en una época particularmente interesante de la historia económica de Vizcaya.

\section{1886-1900: HACIA UNA POLITICA DE INTEGRACIONES VERTICALES}

\subsection{Diversificación de inversiones y grupos empresariales}

Si partimos del capital invertido en las nuevas Sociedades creadas en estos años y su distribución por sectores podemos observar que destacan especialmente dos, el de negocios mineros y el de transporte marítimo, que son también los primeros por el número de Sociedades creadas. También es importante el peso de sectores como el químico o el de las compañías ferroviarias, con bajos porcentajes en número, pero relativamente altos en capital. Ambos alcanzan sus mayores cifras absolutas y relativas ahora. Parecidos porcentajes, aunque de muy diferente significación, muestran eléctricas y siderometalúr-

\section{CUADRO 1}

Número y capital de las Sociedades creadas en Vizcaya según sectores de inversión y porcentaje sobre el total (1886-1900)

\begin{tabular}{|c|c|c|c|c|}
\hline & Capital * & $\%$ & Número & 9 \\
\hline $\begin{array}{lllllll}\text { Minería } & \ldots & \ldots & \ldots & \ldots & \ldots & \ldots \\
\text { Navieras } & \ldots & \ldots & \ldots & \ldots & \ldots & \ldots \\
\text { Ferrocarril } & \ldots & \ldots & \ldots & \ldots & \ldots & \ldots \\
\text { Químicas } & \ldots & \ldots & \ldots & \ldots & \ldots & \ldots \\
\text { Siderometalurgia } & \ldots & \ldots & \ldots & \ldots \\
\text { Eléctricas } & \ldots & \ldots & \ldots & \ldots & \ldots & \ldots \\
\text { Banca-Seguros } & \ldots & \ldots & \ldots & \ldots & \ldots \\
\text { Construcción } & \ldots & \ldots & \ldots & \ldots & \ldots\end{array}$ & $\begin{array}{l}115,7 \\
96 \\
56,6 \\
47,2 \\
34,1 \\
30,8 \\
26,9 \\
12,2\end{array}$ & $\begin{array}{c}23,1 \\
19,1 \\
11,3 \\
9,4 \\
6,8 \\
6,04 \\
5,4 \\
2,4\end{array}$ & $\begin{array}{r}122 \\
90 \\
20 \\
39 \\
85 \\
32 \\
9 \\
57\end{array}$ & $\begin{array}{r}16,6 \\
12,2 \\
2,7 \\
5,3 \\
11,6 \\
4,3 \\
1,2 \\
7,7\end{array}$ \\
\hline
\end{tabular}

* Millones de pesetas.

FuENTE: Registro Mercantil de Vizcaya, Libros de Sociedades. Elaboración propia. 
gicas, las primeras con un elevado capital medio por Sociedad ${ }^{\circ}$. Por último, hay que señalar la escasa importancia del sector de banca y seguros en esta etapa: salvo el Banco de Comercio (1891) ${ }^{7}$, no hay ninguna iniciativa de relieve hasta 1900. El sector de la construcción, a pesar de su cuarto puesto por número, moviliza muy poco capital.

Las cifras de inversores e inversiones, referidas a las Sociedades recogidas en nuestra investigación, vienen a corroborar lo ya comentado. Destaca, sobre todo, el predominio de las compañías navieras, debido fundamentalmente a la hegemonía casi absoluta de la sociedad anónima ${ }^{8}$, con un elevado número de socios por compañía; socios que invierten en más de una Sociedad.

En conclusión, hay una patente diversificación de inversiones con dos sectores punta, las compañías mineras y las navieras. Se produce, además, un auge de las compañías ferroviarias y de las químicas ${ }^{9}$, que reciben bastante

\section{CUADRO 2}

Inversores e inversiones en Vizcaya (1886-1900)

\begin{tabular}{|c|c|c|c|c|}
\hline & \multicolumn{2}{|c|}{ INVERSORES } & \multicolumn{2}{|c|}{ INVERSIONES } \\
\hline & Número & $\%$ & Número & $\%$ \\
\hline 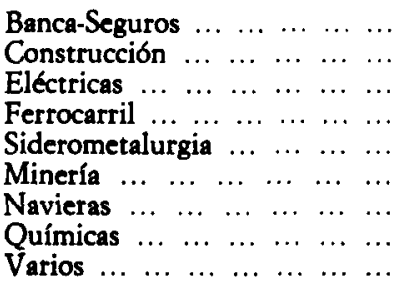 & $\begin{array}{r}22 \\
70 \\
82 \\
170 \\
132 \\
266 \\
282 \\
118 \\
102\end{array}$ & $\begin{array}{r}1,8 \\
5,6 \\
6,6 \\
13,7 \\
10,6 \\
21,4 \\
22,7 \\
9,5 \\
8,2\end{array}$ & $\begin{array}{r}23 \\
74 \\
97 \\
208 \\
185 \\
340 \\
693 \\
138 \\
105\end{array}$ & $\begin{array}{r}1,2 \\
4,0 \\
5,2 \\
11,2 \\
9,9 \\
18,2 \\
37,2 \\
7,4 \\
5,6\end{array}$ \\
\hline $\begin{array}{llllll}\text { TотаL } & \ldots & \ldots & \ldots & \ldots & \ldots\end{array}$ & 1.244 & 100,0 & 1.863 & 100,0 \\
\hline
\end{tabular}

FUENTE: RMV, Libros de Sociedades. Elaboración propia.

- El capital medio de las Sociedades del sector eléctrico no llega al millón de pesetas por muy poco (962.500), mientras que el de las siderometalúrgicas justo alcanza las 400.000 .

7 Registro Mercantil de Vizcaya (en adelante, RMV), Libro 5, Hoja 219.

- En nuestros datos sólo hay anónimas entre las navieras. No obstante, una mínima parte adoptó otras formas jurídicas.

- El auge de las compañías ferroviarias se debe fundamentalmente a la extensión del tendido de líneas por el País Vasco y a la construcción de líneas que enlazan centros mineros, principalmente Santander y Asturias y la cuenca hullera del norte de León, con Bilbao. El de las químicas está muy ligado a la rama de explosivos, muy necesarios para la minería. 
capital. Por el contrario, sectores más significativos en número, como el siderometalúrgico o el de la construcción, reciben menores cantidades de capital, principalmente porque la etapa de intensa inversión en estos sectores se produjo antes, en el período $1879-1882^{10}$.

A continuación vamos a analizar los principales grupos empresariales de esta primera etapa. El grupo Martínez de las Rivas es el primero en urilizar los mecanismos de integración vertical para expansionarse económicamente ". Con un capital, en parte, basado en negocios vinculados al sector público ${ }^{12}$, adquiere en 1879 una fábrica siderúrgica a la compañía inglesa The Cantabrian Iron Company Limited, la futura San Francisco ${ }^{13}$. A partir de 1889 comienza la «etapa naviera» del grupo: José $M{ }^{2}{ }^{2}$ Martínez de las Rivas funda, junto a Ch. M. Palmer, la Compañía Martínez-Palmer ${ }^{14}$. Dos años más tarde crean las Compañias de los vapores Rivas, Mudela y Marqués de Mudela ${ }^{15}$. En ese mismo año -1891-, la antigua Sociedad Martinez Rivas-Palmer se transforma en Astilleros del Nervión ${ }^{16}$, cuyo objetivo inicial es construir tres buques para la Armada Española ${ }^{17}$. En 1894, con los mismos socios que se reinscribe la San Francisco, Alzaga y Procter, crean la Compañia Coto del Musel, situada fuera de Vizcaya ${ }^{18}$. En líneas generales, el grupo diversifica sus in. versiones dentro de un panorama de actividades estrechamente relacionadas entre sí: minería-siderurgia-construcción naval-transporte marítimo.

El grupo Sota y Aznar se encuentra ahora en su fase de conformación. A partir de 1889 y hasta 1899 se fundan por el grupo un total de veinticinco compañías navieras, una por cada buque. Además de este negocio de transporte, el grupo era propietario de la Compañia minera de Setares ${ }^{19}$, cuyo mineral se transportaba casi en su totalidad por su flota de vapores. Gracias a esta integración vertical «del negocio minero y el transporte de su mineral» ${ }^{20}$ se cimentó buena parte de su fortuna. Una prueba significativa de lo que acabamos de afirmar será la rápida adquisición por el grupo de nuevas minas cuando los yacimientos del Norte den muestras de agotamiento: en

1 Sobre esa etapa puede verse Fernández de Pinedo (1983).

"Fernández de Pinedo (1985 a), p. 22.

12 Fernández de Pinedo (1985 $b$ ), en prensa.

13 Fernández de Pinedo (1985 b). Una inscripción de la misma puede verse en el RMV, L. 8, H. 345 (1894). Los socios que aparecen son J. M.' Martínez de las Rivas, J. B. Alzaga y E. W. Procter.

${ }_{14}$ RMV, L. 3, H. 139 (1889).

15 Sus inscripciones respectivas se encuentran en RMV, L. 5, H. 216; L. 5, H. 214, y L. 5, H. 215 (1891).

i6 RMV, L. 5, H. 201 (1891); Ybarra (1947), p. 217.

17 Fernández de Pinedo (1983), p. 17.

"RMV, L. 8, H. 337 (1894).

19 RMV, L. 1, H. 12 (1886).

20 Fernández de Pinedo (1985 a), p. 22. 
1900 crean la Compañia minera de Sierra Menera ${ }^{21}$, con un capital de $32 \mathrm{mi}$ llones de pesetas, compañía que se dedicará a explotar el coto minero del mismo nombre (sito en las provincias de Teruel y Guadalajara), arrendado a Cosme Echevarrieta. El mineral, conducido por ferrocarril hasta Sagunto, era embarcado allí en los buques de la compañía ${ }^{22}$. Posteriormente, en ese mismo lugar se levantará la Compañia Siderúrgica del Mediterráneo, en $1917^{23}$, que supondrá la integración completa (extracción-transporte-transformación). Además, este mismo grupo crea en 1900 , junto a otros navieros interesados, la Compañia Euskalduna de Construcción y Reparación de Buques ${ }^{24}$, ejemplo significativo del interés de los navieros por construir sus propios buques. En esta primera etapa, el 65 por 100 de los inversores en Astilleros son también navieros ${ }^{25}$.

Otro de los grandes grupos navieros es el de Martínez Rodas, muy diversificado en cuanto a sus inversiones en 1886-1900. Su presencia es fuerte en sectores como el eléctrico, minería y banca y seguros. En 1890, y junto a Víctor Chávarri y otros, crean Hulleras del Turón, iniciando un negocio de exportación de mineral hacia Asturias y retorno con carbón, todo ello en barco ${ }^{26}$. Dos años más tarde crea la Compañia Naviera Unión ${ }^{27}$ y en 1895 la Compañia Maritima Cantabria ${ }^{28}$. Pero el grueso de sus inversiones se centrará en los años finales del siglo: en 1899 participa en la creación de la Sociedad General de Centrales Eléctricas ${ }^{29}$; en 1900 crea la Sociedad Unión. Compañia Maritima, con un capital de 16 millones de pesetas ${ }^{30}$; la también Compañia Marítima la Actividad ${ }^{31}$; la Compañia de Seguros Aurora ${ }^{32}$, con 20 millones de pesetas, y Minas de Cala, con 15 millones de pesetas ${ }^{33}$. El fuerte ritmo de inversiones del grupo en los años de la coyuntura finisecular y la cuantía de las mismas hace suponer que contó con una aportación «extra» de capital que no provino de los beneficios de sus antiguas compañías y que bien pudiera proceder del gran volumen de capital repatriado al perder Es-

RMV, L. 16, H. 770 (1900).

22 Cámara de Comercio, Industria y Navegación de Bilbao (CCINB), Memorias de Sociedades 1902 , Doc. 336 , pp. 5 y ss.

${ }^{23}$ RMV, L. 51, H. 2243 (1917).

24 RMV, L. 15, H. 720 (1900).

${ }^{25}$ Porcentaje extraido de nuestro listado de inversores 1886-1900, elaborado a partir de los datos del Registro Mercantil.

${ }^{26}$ Debo esta información a E. Fernández de Pinedo. La escritura de Hulleras del Turón está en RMV, L. 4, H. 160 (1890).

7 RMV, L. 6, H. 237 (1892).

2 RMV, L. 9, H. 385 (1895).

29 RMV, L. 14, H. 647 (1899).

* RMV, L. 14, H. 677 (1900).

31 RMV, L. 15, H. 760 (1900).

${ }^{32}$ RMV, L. 15, H. 690 (1900).

33 RMV, L. 15, H. 764 (1900). 
paña sus últimas colonias ultramarinas ${ }^{34}$. No obstante, esto no deja de ser una hipótesis. Es, pues, un grupo muy parecido al de Sota y Aznar por las actividades donde desarrolla sus negocios, sobre todo sector servicios y alguna compañía minera, en la que invierte para sacar más rentabilidad a su negocio de transporte.

Los años de fin de siglo, además de suponer una considerable capitalización de la economía vizcaína ${ }^{35}$, fueron también años de gran dinamismo empresarial, referido tanto a los grupos empresariales ya existentes, y que amplían su esfera de influencia, como a los que surgen más claramente en este momento. Así, amparados en la fuerte subida de los fletes en los últimos años del siglo $\mathrm{XIX}^{36}$, se configuran varios grupos navieros como los Aznar TutorArzuaga-Urrutia ${ }^{37}$, Barandiarán-Gómez-Mendialdua ${ }^{38}$, Uriarte-Eguiraun-Cortina-Acillona ${ }^{39}$.

En resumen, y por lo que se refiere a los grupos empresariales centrados en el sector naviero, podemos concluir que hay dos grandes tipos. En primer lugar, los grupos creados antes de la coyuntura finisecular, que son también los más poderosos, están agrupados en estructuras de tipo vertical que integran extracción de mineral y transporte, o transporte y construcción de buques. A finales de esta etapa inician otra vinculación característica mediante la creación de compañías de seguros, como es el caso del grupo Martínez Rodas en 1900 o de Sota y Aznar en 1901. Ya hemos referido anteriormente el interés de este último grupo por tener criaderos para transportar mineral, puesto que su negocio residía en la exportación y transporte de su propio mineral. Es significativo, por otra parte, que el grupo Martínez Rodas, vinculado más al tráfico de cabotaje o con América, cree, en 1900, Minas de Cala ante un previsible descenso del comercio con América tras la pérdida de las colonias: la reorientación de parte de sus actividades hacia el tráfico con Europa se hacía con un negocio de extracción de mineral de por medio. Así, pues, los mecanismos de integración vertical tienen ahora un carácter defensivo frente a la competencia de los buques ingleses. Bien es cierto que proporcionaron a estos grupos (fundamentalmente, Martínez de las Rivas y Sota y Aznar) parte de sus cuantiosos beneficios, pero de su buena marcha económica no podemos

${ }^{34}$ Según Harrison (1983), p. 29, whay una decisión colectiva de invertir en Bilbao los ahorros mantenidos en cuentas de depósito durante la campaña de Cuba (1895-1898), esperando un desenlace del conflicto».

${ }_{35}$ El capital registrado de las nuevas Sociedades creadas en Vizcaya en 1901 no se sobrepasará hasta 1962 en pesetas corrientes, y nunca será alcanzado en pesetas constantes. Los casi 450 millones registrados en Bilbao en 1901 supusieron el 50,9 por 100 de todo el capital constituido ese año en España. Valdaliso (1986), pp. 50-51.

${ }^{36}$ Fernández de Pinedo (1985 b).

37 Valdaliso (1986), p. 121.

39 Ibidem.

39 Ibidem, p. 122. 
deducir un control de los fletes ni una ventajosa competencia sobre la marina inglesa ${ }^{*}$. «Sin duda — señala Fernández de Pinedo-, la exportación de mineral de hierro y la importación de carbón, a través de los fletes, tuvo que suponer un negocio nada despreciable, pero fueron los extranjeros quienes se beneficiaron, dejando las migajas a la flota nacional, tanto vizcaína como no vizcaína, en el último cuarto del siglo XIX» ${ }^{41}$.

En segundo lugar, los grupos navieros creados a fines del siglo XIX aprovechan la fuerte subida de los fletes, que coincide con un aumento del mineral y carbón transportado por la flota bilbaína, invirtiendo algunos de ellos - como Arzuaga y Aznar Tutor- en compañías mineras después de haber invertido en la compra de buques. Pero, además, parece que debió haber «una decisiva participación del capital repatriado de las colonias en el desarrollo de la flota vizcaína" ${ }^{42}$. Ya hemos señalado el caso de Martínez Rodas. El testimonio de Ramón de la Sota, citado por Fernández de Pinedo, es muy significativo:

vizcaínos establecidos en Liverpool, Manila, Habana, etc., sustituyeron los antiguos buques de vela por otros de vapor, creando en poco tiempo una flota de importancia, que alcanzó también considerable desarrollo en los años del pasado siglo ${ }^{43}$.

Cambiando ya de sector, el grupo Ibarra-Vilallonga-Zubiría, parte de cuyo capital es de origen bancario ", crea en 1882 la Sociedad Altos Hornos y Fábrica de Hierro y Acero de Bilbao. Durante estos años proseguirá la inversión en este sector, sobre todo en empresas metalúrgicas que demanden sus inputs a Altos Hornos de Bilbao. De esta forma completan la integración que se iniciaba en la participación de Ibarra y Zubiría en la Orconera y Franco Belga con la intención de obtener mineral barato para su fábrica siderúrgica ${ }^{45}$. A partir de los años noventa, y junto a otros señalados inversores del sector siderometalúrgico como E. Gana y R. Rochelt, crean la Sociedad Tubos Forjados de Bilbao, en 1892, y la Basconia y Alambres del Cadagua, en $1893^{\text {*6. }}$. También invierten en minería del carbón en la cuenca asturiano-leonesa, para conseguir combustible a buen precio ${ }^{47}$; en compañías eléctricas ${ }^{48}$; químicas ${ }^{49}, y$

* Como lo hace González Portilla (1981), vol. I, p. 201.

4 Fernández de Pinedo (1985 a), p. 22.

4 Fernández de Pinedo (1985 b), en prensa.

13 Ibidem.

4 Ibidem.

4s Escudero (1985), en prensa.

4 RMV, L. 6, H. 276 (1892); L. 7, H. 278 (1893), y L. 7, H. 298 (1893).

"Compañia Hullera Vasco Leonesa, RMV, L. 9, H. 357 (1894).

- Electra. Compañía General de Electricidad, RMV, L. 3, H. 136 (1889).

- La Papelera Vizcaína, RMV, L. 4, H. 153 (1890). 
de construcción ${ }^{50}$. La expansión del grupo Ibarra es un claro ejemplo de la estrategia de los siderúrgicos en los años finales del siglo xIx: «practicar una política de sustitución de importaciones, sobre todo de la maquinaria del país y que se hacía venir de fuera» (Fernández Pinedo). De esta forma la demanda de hierro y acero de las nuevas empresas metalúrgicas subsanaría el problema de los mercados para una siderurgia que hasta entonces contaba con una fuerte capacidad productiva sólo parcialmente desarrollada por la falta de demanda ${ }^{31}$. Otros grupos, como el de Chávarri o Echevarría, serán también ejemplos significativos de esta política que se empieza a poner en práctica a partir del Arancel de 1891.

En efecto, el grupo liderado por Víctor Chávarri, inicialmente centrado en la minería, crea en 1882 la Compañía Anónima de Metalurgia y Construcciones la Vizcaya ${ }^{52}$. En 1889 crea la Sociedad Delta Español; Talleres de Deusto, en 1891; la Vasco Belga, en 1892; la Basconia y la Ochandianesa, en 1893; Santa Agueda, en 1896, y Chávarri, Petrement y Cía., en $190{ }^{53}$. Pero, además de las inversiones en el sector siderometalúrgico, el grupo diversifica extraordinariamente sus intereses económicos. Sólo su líder, Víctor Chávarri, aparece en cinco empresas metalúrgicas, seis mineras, cuatro químicas, dos de construcción, tres compañías ferroviarias y una eléctrica ${ }^{34}$.

El grupo Echevarría-Zuricalday, liderado por Federico Echevarría Rotaeche, es, básicamente, el resultado de la unión familiar de un grupo fundamentalmente siderometalúrgico con otro más dedicado a negocios comerciales y de alimentación. Al igual que los dos grupos mencionados anteriormente, la dinámica inversora del grupo Echevarría refleja nítidamente la evolución del sector siderometalúrgico: en 1886 crean una fábrica de transformados metálicos, importando hojadelata inglesa ${ }^{55}$. Dos años más tarde se unen con Goitia y Compañia, creando la primera gran empresa metalúrgica vizcaína, que luego pasará a denominarse Iberia ${ }^{56}$. En 1895 crean El Valle, otra empresa metalúrgica ${ }^{57}$. Sus vínculos con los Zuricalday se inician en la Sociedad Red Telefónica de Bilbao, creada en 1889, y en la Papelera Vizcaina, fundada un año después ${ }^{58}$. En 1893 ya aparecen en la antigua Sociedad Hijos de Zurical-

so Sdad. de los terrenos de la Concordia, RMV, L. 3, H. 122 (1889).

51 Fernández de Pinedo (1983), p. 17.

s2 Fernández de Pinedo (1985 b), en prensa.

${ }_{33}$ RMV, L. 3, H. 129 (1889); L. 5, H. 221 (1891); L. 6, H. 251 (1892); L. 7, H. 278 (1893); L. 7, H. 296 (1893); L. 11, H. 477 (1896), y L. 15, H. 703 (1900).

34 Véase Apéndice.

ss Ecbevarría Hermanos, RMV, L. 1, H. 26 (1886); Fernández de Pinedo (1983), p. 16.

so RMV, L. 2, H. 78 (1888). En 1890 se produce el cambio de nombre: RMV, L. 4, H. 173 (1890).

"RMV, L. 9, H. 399 (1895).

s* RMV, L. 3, H. 121 (1889); L. 4, H. 153 (1890). 
day miembros de las dos familias ${ }^{59}$. Este grupo también invirtió en algunos negocios mineros y en varias compañías navieras ${ }^{60}$.

Como hemos visto, gran parte de los grupos navieros o siderúrgicos invierten en minería por diferentes motivos. Grupos empresariales centrados en este sector son, por ejemplo, el formado por Benigno Salazar, Luiz Salazar y J. M. ${ }^{a}$ Lezama Hormaza, que en estos años crean la Sociedad Carbonífera de Matallana y Salazar y Compañia ${ }^{61}$. Los Gandarias, vinculados al grupo Chávarri por su participación en la Vizcaya ${ }^{62}$, aparecen junto a él en varias Sociedades ${ }^{63}$. Posteriormente crearon la Sociedad Coto Minero de Ollargan y Minas de Alcaracejos ${ }^{64}$. Hay, pues, por parte de estos grupos, una reinversión casi exclusiva en el mismo sector.

Otro grupo de carácter monosectorial, esta vez centrado en el sector eléctrico, es el de Salvatierra-Crespo-Márquez de la Escosura-Zuasti, que proviene, sobre todo, del interior del país. Aunque Bilbao es el domicilio social del capital, todas sus iniciativas se centraron en el resto de España: en 1899, y junto a C. Reinke y W. Reinchard, crean la Electra Martos Valdepeñas y la Electra Industrial de Navarra ${ }^{65}$. Un año más tarde crean la Campañia Eléctrica Peninsular, la Electra Industrial de Gijón y la Electra Industrial Coruñesa ${ }^{\circ}$.

En el sector químico destacan los grupos Gurtubay-Greaves-Arbaiza, dedicado, sobre todo, a la importación y refinado de petróleo y aceites minerales desde $1888^{67}$, y los Errazquin, vinculados a la Sociedad Española de la Dinamita, creada en $1871^{\circ 8}$, y que ahora aparecen en Explosivos de Burceña, Unión Española de Explosivos y Fábrica de Vidrios de Lamiaco ${ }^{69}$.

"RMV, L. 7, H. 291 (1893).

* F. Echevarría y Picavea, Cía. Naviera la Blanca, Cía. Naviera Aurrera y Cía. Maritima la Actividad. Para ver sus inscripciones, véase Valdaliso (1986), p. 152.

${ }^{61}$ RMV, L. 4, H. 162; L. 3, H. 148 (1890).

az Fernández de Pinedo $(1985$ b), en prensa.

- Hulleras del Turón, Anglo Vasco de las Minas de Córdoba, Talleres de Deusto y Vasco Asturiana. Valdaliso (1986), p. 152.

${ }^{4}$ RMV, L. 11, H. 502 (1897); L. 12, H. 555 (1898).

" RMV, L. 13, H. 597; L. 13, H. 613 (1899).

* RMV, L. 15, H. 705; L. 15, H. 709; L. 15, H. 710 (1900).

67 Asociados primero a un francés, Fourcade, en la Sociedad Fourcade y Gurtubay, RMV, L. 2, H. 80 (1888), y más tarde solos en Hijos de Gurtubay, RMV, L. 3, H. 119 (1889). Este grupo también tenía varias Sociedades en el sector alimenticio; véase Valdaliso (1986), pp. 126-127.

* Sobre ella, véase Tortella (1983), p. 434.

6 RMV, L. 10, H. 415 (1895); L. 10, H. 442 (1896); L. 4, H. 181 (1890). Tanto la Sociedad Española de la Dinamita como Explosivos de Burceña quedaron fusionadas en la Unión Española de Explosivos, que al año siguiente controló el mercado español gracias al monopolio concedido por el Estado. Sobre esto, véase Tortella (1983), pp. 448-449. 


\subsection{Los inversores y el origen de los capitales}

Debido a las limitaciones de las fuentes, ya expuestas anteriormente, nuestras conclusiones en este apartado concreto se basan en la presencia de los inversores en las diferentes compañías y sectores y no en el volumen de capital suscrito por cada uno. A pesar de ello, creemos que los resultados son indicativos de las inversiones realizadas y de las relaciones intersectoriales en materia de inversión.

Por lo que se refiere a la presencia de capital extranjero, ésta es importante en el sector químico, con un 15,2 por 100 de los inversores. Los restantes sectores con participación de capital extranjero, por orden decreciente, son el eléctrico, con un 9,7 por 100 de los inversores; minería, con un 9,02 por 100, y compañías ferroviarias, con un 8,2 por 100 . En los restantes sectores la presencia es mínima. La mayor intervención de capital extranjero en el sector químico es normal teniendo en cuenta la escasa tradición de la industria química en España, que ha provocado que la mayoría de las iniciativas hayan venido de la mano de empresarios foráneos ${ }^{70}$. En vizcaya son, sobre todo, franceses y alemanes, vinculados a la fabricación de explosivos ${ }^{7}$. También es importante la actuación de aquellos últimos en el sector eléctrico.

Dentro del sector químico también hay que reseñar la presencia de capital asturiano, especialmente inversores del "Grupo Ovetense» como J. Tartiere y L. de Vereterra, agrupados en la Sociedad Industrial Asturiana Santa Bárbara ${ }^{72}$, que aparecen en la Vasco Asturiana de Explosivos y en la Unión Española de Explosivos ${ }^{73}$. Del mismo grupo está A. López, que invierte en compañías ferroviarias como la Constructora de Zalla a Solares y la Compañia de los Ferrocarriles de Santander a Bilbao ${ }^{74}$. Recíprocamente, parece que la presencia de capital vasco fue muy importante en Asturias en los años finales del siglo $\mathrm{XIX}^{75}$.

A pesar de las continuas referencias a la importancia del capital repatriado invertido en Vizcaya al perder España Cuba y Filipinas ${ }^{76}$, no nos ha sido posible cuantificar su presencia. Tampoco conocemos apenas a los inversores que habían hecho su fortuna en las colonias, salvo los casos de E. Aresti Torre ${ }^{n}$

20. Sobre la industria química española, véase Nadal (1986).

7 Véase Tortella (1983), pp. $432-434$ y 449.

${ }^{2}$ Vázquez García (1980), p. 177.

"3 La Vasco Asturiana también se integró en la UEE. Tortella (1983), pp. 448-449.

34 RMV, L. 7, H. 304 (1893); L. 9, H. 398 (1895). La primera acabará por fusionarse junto con otras para crear esta última. Véase Valdaliso (1986), p. 104, nota 20.

75 Vázquez García (1980), pp. 178-179.

76 Véase la nota 34 . En el artículo de Harrison se pueden encontrar referencias de más autores.

$\pi$ Escudero (1986), vol. I, p. 249. 
o Martínez de Pinillos ${ }^{78}$. Por el momento, sólo un seguimiento personal de los inversores proporcionará algún dato al respecto.

A continuación vamos a analizar las relaciones intersectoriales entre los inversores. La teoría tradicional de la industrialización de Vizcaya hace de la minería el sector de arrastre fundamental del posterior desarrollo industrial de la provincia. La burguesía minera vasca, exportadora de mineral, fue, según esta interpretación, «el eje, a nivel empresarial, del desarrollo industrial y del capitalismo en el País Vasco" ${ }^{79}$. La intensa acumulación de capital realizada en el sector minero por un «reducido grupo de empresarios (...) fue decisiva (...) en la financiación del desarrollo económico de Vizcaya y del País Vasco en el último cuarto del siglo $\mathrm{XIX}^{\mathrm{80}}{ }^{80}$. La reinversión de este capital sirvió para crear una moderna industria siderúrgica $\mathrm{y}$, más concretamente en esta primera etapa, para "la financiación total de la expansión siderúrgica vizcaína» ${ }^{81}$.

A fin de calibrar de alguna manera la importancia de la minería y de la burguesía minera, hemos cuantificado la presencia, en cada uno de los sectores, de los inversores en minería y el porcentaje que representan en cada sector. Asimismo, y para realizar una comparación, hemos hecho algo idéntico con los inversores en siderometalurgia. Antes de analizar los resultados hay que hacer ciertas matizaciones. En primer lugar, cuando hablamos de capital minero, siderúrgico, bancario, etc., estamos recurriendo a una generalización para sistematizar los datos, pues es casi imposible averiguar la procedencia exacta de un determinado capital. En segundo lugar, y dado que operamos con un listado de inversores e inversiones de 1886 a 1900 , hay que tener en cuenta la cronología de estas últimas. A este respecto, Fernández de Pinedo, para el caso concreto de la minería, ha señalado el hecho de «que ciertos inversores de 1882 , cuando se iniciaba la gran exportación de mineral, figuren como mineros en 1890 no garantiza que el capital invertido a principios de los ochenta haya tenido sus raíces en la minería» ${ }^{82}$. Por último, en los sectores están agrupados tanto las actividades directamente productivas como las comerciales; por ejemplo, en nuestra lista de inversores en minería habrá tanto mineros productores, que laborean minas propias o arrendadas, como individuos que se dediquen al comercio del mineral.

" Que fue secretario general de la Cámara de Comercio de La Habana en 1889. CCINB, Fondo Julio de Lazúrtegui, Carpeta 54, núm. 18: Informe sobre una exposición de la Sociedad de Estudios Económicos acerca del comercio de cabotaje en la metrópoli, CCIN de La Habana, 1889.

Tonźllez Portilla (1981), vol. I, p. 70.

Ibidem, p. 71.

"Lequerica (1956), p. 47; González Portilla (1981), vol. I, p. 96; Banco de Bilbao (1957), p. 167.

a Fernández de Pinedo (1985 b), en prensa. 
$\mathrm{Si}$ analizamos el número total de los inversores en negocios mineros ${ }^{\text {a }}$ podemos inferir de su cantidad que los beneficios de este sector «no se concentraron exclusivamente entre la gran burguesía minera, sino que más de un tercio de los mismos se desparramó entre las clases medias" ". En efecto, se constituyeron gran número de compañías por parte de burgueses que no eran los Martínez Rivas, Chávarri, Gandarias, Durañona o Lezama; burgueses que formaron «una numerosa clase media que supo aprovechar lo fácil y barato de los registros» ${ }^{85}$. Hay que tener en cuenta que nuestro listado de inversores en minería (1886-1900) corresponde a un 52,4 por 100 de las compañias mineras creadas en este período, porcentaje que se refiere a las compañías mineras más importantes $o$, a lo sumo, de tamaño medio. Las pequeñas compañías, generalmente colectivas, que laborean una o varias minas, se encuentran en ese 47,6 por 100 que no hemos recogido.

Por lo que se refiere a los porcentajes de participación de inversores mineros y siderometalúrgicos, vemos que la presencia de los primeros sobrepasa el 20 por 100 en el sector siderometalúrgico, químico y construcción. En los restantes sectores el porcentaje de mineros entre sus inversores oscila entre el

\section{CUADRO 3}

Presencia de inversores en mineria $y$ en siderometalurgia en los demás sectores (1886-1900)

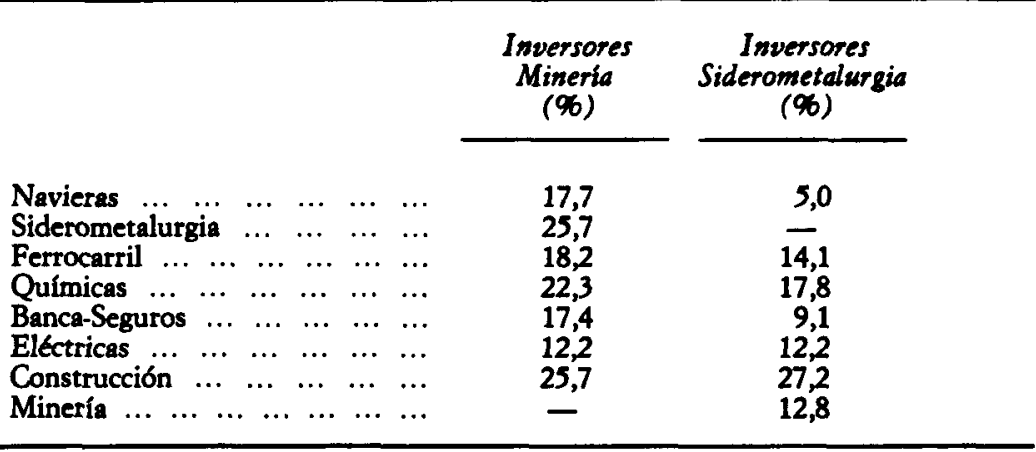

FUENTE: RMV, Libros de Sociedades, listado de inversores 1886-1900. Elaboración propia.

"Que son más de 500 en el período 1886-1913. Dato extraído de nuestros listados de inversores del RMV, 1886-1900 y 1901-1913.

Hscudero (1985), en prensa.

is Ibidem. 
12 y el 18 por 100 . La presencia de inversores en siderometalurgia, aun siendo considerablemente menores en número que los primeros ${ }^{86}$, es importante en construcción, químicas y ferrocarril, teniendo porcentajes parecidos en minería y eléctricas. A primera vista, de estas cifras se deduce una contribución importante de la minería, pero de ningún modo fundamental, ni decisiva, cara al surgimiento de una industria moderna. Los relativamente altos porcentajes en químicas, ferrocarril y, sobre todo, construcción obedecen a la fuerte atracción que ejercieron como receptores de capital y diversificadores de inversiones. Tanto inversores mineros como siderometalúrgicos aparecen en ellos con parecida importancia. La diferencia a favor de los primeros estriba en el mayor desarrollo y proliferación de compañías mineras en esta etapa, mientras que el ritmo de creación de compañías siderometalúrgicas no se incrementa hasta iniciada la década de los noventa, ritmos diferentes que influyen en el mayor o menor número de inversores en cada sector. No obstante, eso no les impide ser a los inversores en siderometalurgia los que tengan un porcentaje más alto en el sector de la construcción e igualen a los mineros en el sector eléctrico.

Los porcentajes de inversores mineros en los sectores siderometalúrgico y naviero se explican por otros motivos. Ya hemos visto que algunos grupos navieros integraban verticalmente el negocio de extracción de mineral y su posterior transporte, pero las inversiones en minería no fueron siempre el punto de partida para una posterior adquisición de buques. Grupos como el de Martínez Rodas o el de Arzuaga-Urrutia invirtieron en minería para poder transportar mineral en sus buques, mineral que mayoritariamente era embarcado en buques extranjeros ${ }^{87}$. $\mathrm{El}$ mismo Sota invirtió en el sector naviero siendo antes minero, pero en 1900 invirtió de nuevo en minería para asegurar la prosperidad económica de su flota de vapores, sin que sepamos hasta qué punto el capital empleado provino de la minería o del transporte marítimo. En el caso de los grupos siderometalúrgicos, el único que previamente tiene negocios de minas es el de los Chávarri ${ }^{88}$. Los dos restantes invierten en minería a posteriori de sus inversiones en el sector siderometalúrgico. Con esto no pretendemos en ningún momento negar la existencia de una corriente reinversora de beneficios mineros en la industria y los servicios, pero sí cuestionar que fuera la única o la predominante. Las corrientes de reinversión fueron múltiples y recíprocas, dentro de una fuẹrte tendencia a diversificar las inversiones. Además, salvo los Chávarri, los restantes grupos que muestran un acusado dinamismo inversor no son precisamente mineros. La tendencia

- Véase cuadro 2.

7 Fernández de Pinedo (1985 a), pp. 21-22; Fernández de Pinedo (1985 b), cuadros 8 y 9, en prensa.

" Y tampoco se le puede calificar exclusivamente de minero. Véase Fernández de Pinedo (1985 b), en prensa. 
de estos últimos se dirigirá hacia la reinversión en el mismo sector, como es el caso de Lezama, Salazar o Gandarias.

En conclusión, pues, hay que cuestionar la rotundidad de las afirmaciones de la teoría tradicional sobre la contribución de la minería a la industrialización de Vizcaya. De lo expuesto hasta el momento se deduce una cierta importancia de este sector; importancia que no es explicativa por sí sola del acelerado ritmo de industrialización que vive Vizcaya en estos años.

\section{1901-1913: UN PERIODO DE CONCENTRACION EMPRESARIAL}

\subsection{Diversificación de inversiones y grupos empresariales}

Partiendo de nuevo del capital invertido en los diferentes sectores y comparándolo con el de la etapa anterior, podemos apreciar varias diferencias. En primer lugar, hay un importante aumento del capital invertido, que se hace más perceptible en los primeros sectores del cuadro, banca y seguros y minería, cuyas diferencias con los restantes sectores son significativas. Asimismo, las diferencias entre el tercer y cuarto sector y los restantes también son importantes. Prueba de la concentración de las inversiones en este período es el hecho de que ahora los cuatro primeros sectores reúnen el 70,1 por 100 del capital total invertido en Vizcaya, por tan sólo el 29,7 por 100 en cuanto al número de sociedades, mientras que en la etapa anterior los porcentajes respec-

\section{CUADRO 4}

Número y capital Sociedades creadas en Vizcaya según sectores de inversión y porcentaje sobre el total (1901-1913)

\begin{tabular}{|c|c|c|c|c|}
\hline & Capital * & $\%$ & Número & $\%$ \\
\hline 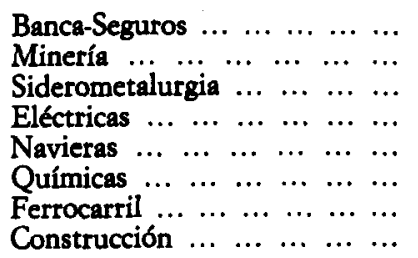 & $\begin{array}{c}200,0 \\
183,4 \\
98,02 \\
83,3 \\
41,9 \\
38,3 \\
30,4 \\
23,0\end{array}$ & $\begin{array}{r}24,8 \\
22,8 \\
12,2 \\
10,3 \\
5,2 \\
4,7 \\
3,8 \\
2,8\end{array}$ & $\begin{array}{r}27 \\
162 \\
89 \\
47 \\
64 \\
47 \\
7 \\
81\end{array}$ & $\begin{array}{r}2,5 \\
14,8 \\
8,1 \\
4,3 \\
5,8 \\
4,3 \\
0,6 \\
7,4\end{array}$ \\
\hline
\end{tabular}

* Millones de pesetas.

FuENTE: RMV, Libros de Sociedades. Elaboración propia. 
tivos fueron 62,9 y 36,8 por 100 . Ha habido, pues, un aumento de capital absorbido por los principales sectores en este período 1901-1913, capital concentrado en un menor número de sociedades. En estos años se crean grandes compañías como Altos Hornos de Vizcaya, Hidroeléctrica Ibérica, Banco de Vizcaya, etc. En contraste con ese gigantismo empresarial, también ahora aumenta considerablemente el número de pequeñas compañias, la mayoría de ellas no encuadradas en los sectores básicos de inversión y con tan sólo un 13,4 por 100 del capital total.

Por sectores, tanto banca y seguros como minería son los más importantes en cuanto a capital recibido, siendo, además, este último el primero en número. El sector siderometalúrgico y el eléctrico experimentan una fuerte subida en capital, aun cuando sus porcentajes en número disminuyan o permanezcan igual, lo que nos indica un aumento del capital medio por empresa en ambos. Por el contrario, las compañías navieras y los ferrocarriles descienden fuertemente en número y capital como consecuencia de las crisis en sus respectivos sectores. La industria de la construcción permanece igual en porcentajes, pero ha visto aumentar el capital dirigido a ella. Las químicas, por último, descienden en número y capital, aunque no considerablemente.

Acorde con ese fenómeno de concentración empresarial que se produce en el período 1901-1913, las cifras de inversores e inversiones referidas a las Sociedades más importantes creadas en estos años también descienden, al igual que el porcentaje de sociedades anónimas, sobre el total, que ahora es del 24,9 por 100 frente al 34,7 por 100 de la etapa anterior. El predominio del sector

\section{CUADRO 5}

Inversores e inversiones en Vizcaya (1901-1913)

\begin{tabular}{|c|c|c|c|c|}
\hline & \multicolumn{2}{|c|}{ INVERSORES } & \multicolumn{2}{|c|}{ INVERSIONES } \\
\hline & Número & $\%$ & Número & $\%$ \\
\hline 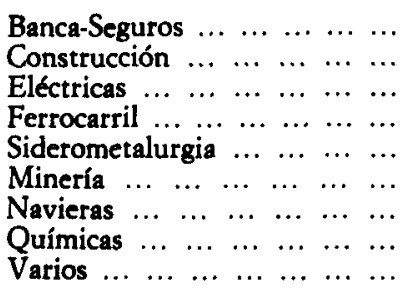 & $\begin{array}{r}91 \\
53 \\
103 \\
20 \\
56 \\
348 \\
70 \\
38 \\
144\end{array}$ & $\begin{array}{r}9,8 \\
5,7 \\
11,1 \\
2,2 \\
6,1 \\
37,7 \\
7,6 \\
4,1 \\
15,6\end{array}$ & $\begin{array}{r}95 \\
55 \\
111 \\
23 \\
65 \\
436 \\
78 \\
39 \\
169\end{array}$ & $\begin{array}{r}8,9 \\
5,1 \\
10,4 \\
2,1 \\
6,1 \\
40,7 \\
7,3 \\
3,6 \\
15,8\end{array}$ \\
\hline $\begin{array}{lllllll}\text { TotAL } & \ldots & \ldots & \ldots & \ldots & \ldots\end{array}$ & 923 & 100,0 & 1.071 & 100,0 \\
\hline
\end{tabular}

FUENTE: RMV, Libros de Sociedades. Elaboración propia. 
minero en cuanto al número de inversores e inversiones es abrumador en esta etapa, lo que se debe fundamentalmente a la gran importancia de las compañias mineras creadas en estos años, con grandes volúmenes de capital; compañías que en su inmensa mayoría se dedicaron a laborear minas situadas fuera de la provincia. Si en el período $1886-1913$ el 77,7 por 100 de las grandes Sociedades (el 48 por 100 del total) se dedicaron a explotar minas fuera de Vizcaya, en $1901-1913$ el porcentaje asciende hasta el 82,4 por $100^{89}$. El número de inversores también aumenta en banca y seguros, eléctricas y varios, aumento relacionado con el especial auge que los dos primeros sectores experimentan en esta época.

Todos los datos apuntan, en suma, a que en estos años se produjo una creciente concentración industrial y empresarial no sólo en Vizcaya, sino en todo el país ${ }^{90}$. A la vez, no hay que olvidar el desarrollo de los grandes bancos, que en Vizcaya tuvieron un carácter mixto, lo que pudo suponer una diversificación de inversiones indirecta a trạés de la banca ${ }^{91}$.

El grupo de Martínez de las Rivas no aparece ahora en ninguna nueva Sociedad. Hasta 1918 no volverá a participar en ninguna iniciativa, año en el que crea, junto a otros inversores, la Hispano Portuguesa de Transportes Eléctricos, perteneciendo a su Consejo de Administración ${ }^{92}$.

El grupo Sota y Aznar experimenta una profunda transformación en la primera década del nuevo siglo. En primer lugar, los tres socios mayoritarios de las compañías de buques, Ramón de la Sota, E. Aznar de la Sota y Luis M. Aanar y Tutor, crean en 1901 la sociedad colectiva Sota y Aznar ${ }^{93}$, como forma de gestionar sus intereses y agrupar sus acciones en las compañías de los diferentes buques y en las Sociedades mineras del grupo. En ese mismo año, y junto a José Luis Costa y J. L. Villabaso, este último vinculado a Sota desde la creación del Banco de Comercio en 1891, crean la Sociedad más grande del período, la Polar de Seguros, con un capital de 100 millones de pesetas ${ }^{94}$. Siguiendo el ejemplo del grupo Martínez Rodas, el grupo Sota y Aznar creó también una compañía de seguros con la doble finalidad de asegurar su propia flota y ofertar sus servicios a otras compañías navieras o industriales ${ }^{95}$. En 1901 también, Ramón de la Sota participa en la fusión del Banco de Comercio con el de Bilbao y en la creación de otras compañías*. En 1906, si-

- Para averiguar cuáles eran las compañías que laboreaban minas fuera de Vizcaya he contado con la inestimable ayuda de A. Escudero.

* Tuñón de Lara (1983), pp. 410-411; Maluquer de Motes (1987), p. 63.

91 Sudriá (1985), p. 262.

92 RMV, L. 56, H. 2479 (1918).

${ }^{3}$ RMV, L. 16, H. 799 (1901).

* RMV, L. 16, H. 830 (1901).

"s Debo esta información a E. Fernández de Pinedo.

* Banco de Bilbao, RMV, L. 16, H. 850 (1901). En esta fusión aparecen como socios 
guiendo la estrategia particular del sector, se produce la fusión de las veintitrés compañías de buques existentes bajo el nombre de la Compañia Naviera Sota y Aznar, S. A., con un capital de 9,5 millones de pesetas ${ }^{97}$. En resumen, hay una reorganización del grupo, tendente a un mayor control, por parte de sus tres figuras principales, de todas las actividades en donde está presente.

En torno al Banco Vascongado, creado en 1902 y posteriormente integrado en el Vizcaya ${ }^{98}$, se produce una clara articulación de lo que hasta entonces habían sido grupos empresariales dispersos, que a partir de ahora tendrán más conexiones entre sí. Este banco nace de la participación de la Compañía de Seguros Aurora, del grupo Martínez Rodas, y de la fusión del Banco NavieroMinero ${ }^{99}$, en el que participan diversos grupos.

El grupo Ibarra-Vilallonga-Zubiría dirige su atención preferentemente hacia el dinámico sector de las eléctricas, participando fuertemente en compañías como la Hidroeléctrica Ibérica, Compañía Ibérica de Electricidad Thomson Houston y Unión Eléctrica Vizcaina ${ }^{100}$, e indirectamente en algunas más a través del Banco de Vizcaya, en cuyo Consejo de Administración están presentes ${ }^{101}$. Maluquer ha puesto de relieve la importancia de este banco, eje de "un trust perfectamente articulado» de grandes empresas eléctricas ${ }^{102}$. Junto a otros grupos participará en la creación de Saltos del Ter, en $1907^{103}$, y es, además, uno de los grupos creadores del gigante Altos Hornos de Vizcaya, junto a los Chávarri y Echevarría ${ }^{104}$. También aparece en varias compañías mineras ${ }^{105}$.

ejecutores, por el Banco de Bilbao, Tomás de Epalza, R. de Ibarra y Arregui, E. Coste, C. Uríen, M. Mac Mahón, A. Galina, R. Velilla e I. de Arias; por el Banco de Comercio, Ramón de la Sota, M. Lezama Leguizamón, M. Mendirichaga, R. Amézaga, F. Larrinaga, J. A. Uriarte, F. de Arteche y L. Ansuátegui.

$\because$ RMV, L. 28 , H. 1328 (1906). El capital estaba dividido en 19.000 acciones de 500 pesetas cada una, de las que la Sociedad Sota y Aznar poseía 7.857, el 41,3 por 100 del total. Datos extraídos del Informe de la Comisión nombrada para llevar a cabo la fusión de las Compañías de los buques..., CCINB, Memorias de Sociedades 1906, Doc. 486.

* Escudero (1986), vol. I, p. 267.

- Véase Apéndice. Las inscripciones de las diferentes Sociedades se encuentran en Valdaliso (1986), p. 154.

${ }^{100}$ RMV, L. 17, H. 901 (1901); L. 17, H. 920 (1901); L. 33, H. 1491 (1908). En ellas también se encuentra el grupo Aznar-Arzuaga...

${ }^{101}$ RMV, L. 16, H. 825 (1901). Los socios fundadores fueron P. Mac Mahón Aguirre, T. Urquijo Aguirre, P. Maíz Arzuaga, R. Picavea Leguía y J. M. Basterra, todos ellos en el Consejo de Administración. La información sobre los Ibarra la hemos tomado de Ybarra (1947), p. 213.

${ }^{102}$ Maluquer (1985), pp. 247-248.

${ }^{103}$ Véase Apéndice.

${ }^{104}$ RMV, L. 19, H. 1023 (1902). La Sociedad Altos Hornos de Vizcaya es fruto de la fusión de Alıos Hornos y Fábricas de Hierro y Acero de Bilbao, la Vizcaya y la Iberia.

${ }^{105}$ Cía. Vascongada de Minería, RMV, L. 17, H. 867 (1901); Minas de Irún y Lesaca, RMV, L. 17, H. 877 (1901), y Sdad. Minera Vasco Catalana, RMV, L. 30, H. 1382 (1907). 
El grupo Echevarría-Zuricalday mantiene sus inversiones en los sectores metalúrgico y alimentación (véase Apéndice), pero en las iniciativas más destacadas en las que participa está asociado a R. Picavea Leguía, creador, con I. García Lastra, de Hispania. Compañia General de Alumbrado ${ }^{106}$. En 1901, junto a C. Reinke y J. Ahlemeyer, crean primero Ablemeyer, $S$. A., y poco más tarde Ablemeyer, Compañia Anónima de Construcciones e Instalaciones Electromecánicas, fruto de la fusión de la anterior con la Hispania ${ }^{107}$. Un año más tarde este mismo grupo crea la Hidroeléctrica de Cataluña, con un capital de 10 millones de pesetas ${ }^{108}$. En 1907, tanto Echevarría como Picavea participan en la creación de Saltos del Ter. No es extraño, pues, que R. Picavea sea uno de los socios fundadores del Banco de Vizcaya, el banco eléctrico por excelencia ${ }^{109}$.

El grupo bancario Crédito de la Unión Minera está formado por un gran número de mineros cuyas inversiones básicas y fundamentales siguen centrándose en el sector del que proceden ${ }^{110}$. El grupo principal en este banco, aparte de los Chávarri, es el Gandarias, familia minera muy importante en Vizcaya desde los años ochenta del pasado siglo "'I.

Los Chávarri mantienen su política de diversificación, ahora no sólo de inversiones, sino también de relaciones con otros grupos empresariales o empresarios individuales. Por una parte, mantiene una fuerte presencia en el sector minero, participando en seis compañías mineras y en el Crédito de la Unión Minera. En los restantes sectores, la mayoría de las veces aparece asociado a P. Allende y a E. Borda Achúcarro, duo inversor de gran dinamismo, presente sobre todo en compañías ferroviarias ${ }^{112}$. Es, quizás, el grupo empresarial cuyos intereses económicos se encuentran más diversificados.

Como conclusiones generales de este apartado podemos enumerar, en primer lugar, la desaparición de varios grupos navieros como inversores en nuevas compañías y la reorganización de los grupos que perduran a través de una política de fusiones o concentraciones horizontales. Esta se explica por la crisis del sector, que se inicia en 1901 con una brusca caída de los fletes. Así, hasta 1909, las principales iniciativas revisten el carácter de concentraciones horizontales, mientras que las restantes compañias que se crean se dedican

${ }^{106}$ RMV, L. 16, H. 777 (1900).

107 RMV, L. 17, H. 854 (1901); L. 17, H. 907 (1901).

${ }^{100}$ RMV, L. 20, H. 1039 (1902). También participa aquí el grupo Salvatierra-Crespo..., que tras crear la Electra Industrial de Castilla la Nueva, en 1901, y participar en Saltos del Ter desaparece como grupo inversor.

${ }^{109} \mathrm{La}$ expresión es de Maluquer (1985), p. 252.

110 Véase Apéndice.

"in Escudero (1985), en prensa.

${ }^{112} \mathrm{P}$. Allende es vicepresidente de la Cia. de los Ferrocarriles Vascongados, de la que E. Borda es vocal del Consejo de Administración. RMV, L. 29, H. 1356 (1906). También son socios de otras compañías: véase Apéndice. 
fundamentalmente al cabotaje —navegación que sí estaba protegida-, con un capital social menor y una razón jurídica que ya no es la anónima ${ }^{113}$. Además de esa política de fusiones, la estrategia de los navieros se centró en pedir protección al Estado, solicitando una serie de primas a la navegación que se concederán, en 1909, mediante la Ley de Protección a las Industrias y Comunicaciones Maritimas. Parece, pues, que los navieros estuvieron muy interesados en recibir la protección del Estado, lo que pone muy en duda su pretendido librecambismo ${ }^{114}$.

En segundo lugar, la tendencia de la mayoría de los grupos mineros a invertir de nuevo en el mismo sector, sobre todo en compañías mineras situadas fuera de Vizcaya.

Por último, el viraje de grupos tradicionaimente navieros (Aznar TutorArzuaga-Urrutia), o siderometalúrgicos (Ibarra-Vilallonga, Echevarría), hacia una inversión preferente en el sector eléctrico, grupos que participan en la creación del Banco de Vizcaya y pertenecen a su Consejo de Administración. Tendencia a la que no son ajenas las dificultades del sector siderúrgico vasco en la primera década del nuevo siglo.

$\mathrm{Y}$ en todos ellos una profundización de las relaciones con el resto de la burguesía vasca; burguesía que ahora no sólo diversifica sus inversiones como en el período anterior, sino también los grupos y empresarios con los que participa en la creación de numerosas compañías. La confluencia de varios de estos grupos y el fuerte papel de los bancos como cabezas de los grandes grupos de intereses (grupo Sota y Aznar, vinculado al Banco de Bilbao; grupos Ibarra-Vilallonga, Aznar Tutor-Arzuaga-Urrutia y Echevarría-Picavea, en torno al Banco de Vizcaya) confirma la primera impresión de esta etapa como un período de concentración empresarial y financiera.

\subsection{Los inversores y el origen de los capitales}

La presencia del capital extranjero se mantiene en el sector químico con un 15,8 por 100 , pero disminuye o permanece en unos niveles mínimos en los restantes sectores.

El número de inversores, según nuestra muestra, disminuye. Frente a los 913 inversores de la primera etapa ahora sólo hay 760 , de los cuales un 32,9 por 100 fueron inversores en la etapa anterior. Podemos hablar, pues, de una renovación importante en el conjunto de la clase empresarial vasca, aun cuando la mayoría de los grandes «capitanes de empresa» permanezcan.

${ }^{113} \mathrm{La}$ relación completa de las compañías navieras creadas durante estos años está en Valdaliso (1986), p. 157, nota 197.

114 Fernández de Pinedo (1985 a), pp. 24-25. 
Como en el periodo anterior, hemos cuantificado la presencia de los inversores de origen minero en los demás sectores. En primer lugar, y ya que tenemos el listado de inversores de la etapa 1886-1900, podremos constatar la presencia de inversores mineros en los diferentes sectores en el período 1901-1913, lo que nos dará una idea aproximada de dónde invierten los beneficios del período precedente $-\mathrm{y}$, por tanto, una corroboración o una matización de la teoría tradicional ya comentada-. El cuadro 6 trata de reflejar la importancia de los inversores «antiguos» (del período 1886-1900) en los sectores de la etapa 1901-1913. En la columna bajo el nombre de inversores en minería se reflejan los porcentajes de inversores en cada sector que en la etapa anterior fueron inversores en minería. En la siguiente columna se hace lo mismo con los inversores en el sector siderometalúrgico y la última columna recoge los porcentajes de inversores en cada sector que en la etapa 1886-1900 habían invertido en ese mismo sector. De alguna manera esta última columna reflejaría la reinversión de beneficios en el propio sector, una especie de autofinanciación del mismo.

\section{CUADRO 6}

Presencia de inversores en mineria, siderometalurgia y en el propio sector durante 1886-1900, en el periodo 1901-1913

\begin{tabular}{|c|c|c|c|}
\hline & $\begin{array}{l}\text { Inversores } \\
\text { Mineria } \\
(\%)\end{array}$ & $\begin{array}{c}\text { Inversores } \\
\text { Siderometalurgia } \\
(\%)\end{array}$ & $\begin{array}{l}\text { Inversores } \\
\text { mismo sector } \\
(\%)\end{array}$ \\
\hline $\begin{array}{llllllll}\text { Banca-Seguros } & \ldots & \ldots & \ldots & \ldots & \ldots & \ldots \\
\text { Electricas } & \ldots & \ldots & \ldots & \ldots & \ldots & \ldots & \ldots \\
\text { Mineria } & \ldots & \ldots & \ldots & \ldots & \ldots & \ldots & \ldots \\
\text { Químicas } & \ldots & \ldots & \ldots & \ldots & \ldots & \ldots & \ldots \\
\text { Construcción } & \ldots & \ldots & \ldots & \ldots & \ldots & \ldots \\
\text { Siderometalurgia } & \ldots & \ldots & \ldots & \ldots & \ldots & \ldots \\
\text { Navieras } & \ldots & \ldots & \ldots & \ldots & \ldots & \ldots & \ldots \\
\text { Navien } & \ldots & \ldots & \ldots & \ldots\end{array}$ & $\begin{array}{l}23,1 \\
15,5 \\
18,1 \\
13,1 \\
11,3 \\
17,8 \\
15,7\end{array}$ & $\begin{array}{r}7,7 \\
11,6 \\
6,6 \\
2,6 \\
9,4 \\
25,0 \\
-\end{array}$ & $\begin{array}{r}5,5 \\
16,5 \\
18,1 \\
7,9 \\
5,6 \\
25,0 \\
27,1\end{array}$ \\
\hline
\end{tabular}

FuzNTE: RMV, Libros de Sociedades, listados de inversores 1886-1900 y 1901-1913. Elaboración propia.

Analizando los resultados vemos que los porcentajes de la primera columna no son nada espectaculares: tan sólo el sector de banca y seguros refleja un 23,1 por 100 , no llegando los restantes al 20 por 100 . En números reales destaca la elevada presencia de mineros del período 1886-1900 que vuelven 
a invertir en minería, fenómeno que ya hemos visto al hablar de los grupos empresariales. Del total de inversores en minería en el período 1886.1900 que vuelven a invertir en diferentes sectores en 1901-1913, un 80,7 por 100 de los mismos reinvierte sus beneficios de nuevo en compañías mineras, fundamentalmente situadas fuera de Vizcaya, como también ha señalado Escudero ${ }^{115}$. Se puede, a la vista de estos datos, afirmar que los beneficios procedentes de la minería se dirigieron mayoritariamente hacia la creación de compañías mineras en el resto de España.

La presencia de inversores en siderometalurgia también disminuye en todos los sectores, excepto en el propio, en el que llega a significar un 25 por 100, lo que hace suponer que en este sector se produjeron elvados porcntajes de autofinanciación. Algo parecido ocurre en el sector naviero, que presenta cifras de autofinanciación bastante elevadas, cercanas al 30 por 100 , lo que se explica por esa política de concentraciones horizontales llevada a cabo durante la primera década del siglo. Estos porcentajes vienen a corroborar las tesis de Fernández de Pinedo sobre la autofinanciación del sector siderúrgico y sobre la escasa presencia de capital minero en la flota vasca ${ }^{116}$.

Un último dato que, en líneas generales, pone de manifiesto la importancia del sector minero en la industrialización llevada a cabo en el período 1901. 1913. De los 250 inversores del período $1886-1900$ que invierten de nuevo en esta etapa sólo el 31,2 por 100 fueron inversores en minería. Por lo tanto, casi un 70 por 100 pertenecen a otros sectores. Si tenemos en cuenta que de ese 31,2 por 100 de mineros la gran mayoría - un 80,7 por 100 - invierte de nuevo en minería, habrá que concluir que el aporte de capital del sector minero a la industrialización de Vizcaya fue mucho menos importante de lo que hasta ahora se ha sostenido.

Vamos ahora a cuantificar la presencia de inversores en minería en 19011913 en los restantes sectores. No obstante, y teniendo en cuenta que hay un porcentaje no desdeñable de inversores mineros en el periodo anterior que invierten de nuevo en este período, hemos desagregado en la columna 2 el porcentaje de inversores en minería que son, efectivamente, nuevos, esto es, que no invirtieron en 1886-1900, con el objeto de evitar una doble contabilidad de los inversores antiguos en el cuadro anterior y en el presente. Aun sin recurrir a la columna 2, simplemente comparando los porcentajes de la columna 1 (que contabiliza nuevos y antiguos inversores en minería) con los del cuadro 3, vemos que, salvo en el caso de banca y seguros y eléctricas, el porcentaje baja en todos los demás sectores.

11 Escudero (1985), en prensa.

116 Fernández de Pínedo ( 1985 b), en prensa. También Escudero (1986), vol. I, p. 250, analizando los Consejos de Administración de varias compañías navieras, ha señalado lo mismo. 


\section{CUADRO 7}

Presencia de inversores en minería en los demás sectores (1901-1913)

\begin{tabular}{|c|c|c|}
\hline & $\stackrel{1}{(\%)}$ & $\stackrel{2}{2} \%$ \\
\hline 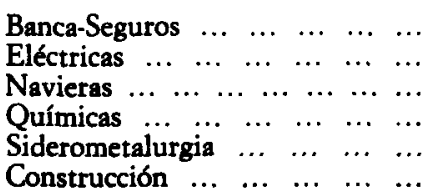 & $\begin{array}{l}28,6 \\
17,5 \\
15,7 \\
18,4 \\
21,4 \\
15,1\end{array}$ & $\begin{array}{r}16,5 \\
10,7 \\
5,7 \\
10,5 \\
8,9 \\
7,5\end{array}$ \\
\hline
\end{tabular}

FUENTE: RMV, Libros de Sociedades, listados de inversores 1886-1900 y 1901-1013. Elaboración propia.

De todo lo expuesto parece cuando menos arriesgado sostener afirmaciones como que la burguesía vasca exportadora de mineral «fue el eje, a nivel empresarial, del desarrollo industrial y del capitalismo en el País Vasco" ${ }^{117}$. La presencia de esta burguesía explica tan sólo una mínima parte del desarrollo industrial de Vizcaya. Además, sus intereses se dirigieron primordialmente a la explotación de yacimientos mineros en el resto del Estado español.

\section{CONCLUSIONES}

Aunque el auge de algunos sectores tales como banca y seguros o eléctricas se produce a partir de 1901, hay una profunda diversificación de inversiones desde los años ochenta del siglo xIx. La mayoría de los grupos empresariales se centra en más de un sector, realizando, además, «incursiones» en otros campos de actividad económica. Con ello no sólo disminuyen el riesgo que toda inversión lleva consigo, sino que también estrechan las relaciones con otros sectores de la burguesía vasca y española.

En las condiciones descritas, la sociedad anónima aparecía como la forma jurídica ideal que posibilitaba una rápida captación de capitales y una fácil participación de los inversores en cualquier sector de la actividad económica, sin verse obligados a llevar la gestión de la empresa. Lo mismo sucede en Asturias, donde diversificación inversora y generalización de la sociedad anónima son hechos paralelos ${ }^{118}$. Estos factores, junto a la intensa capitalización

117 Véase nota 79.

"11 Vázquez García (1980), p. 175. 
de la época, originaron la generalización de la sociedad anónima en Vizcaya. La importancia de la misma, especialmente en la primera etapa 1886-1900, donde supone el 34,7 por 100 del total de las Sociedades constituidas en Vizcaya, no se superará hasta después de la guerra civil.

La dinámica inversora de los grupos empresariales es un fiel indicador de la estrategia que se desarrolla en cada sector. Durante el período 1886-1913 se produce:

- Un intenso ritmo de creación de compañías navieras en los años finales del siglo XIX, aprovechándose de la espectacular subida de los fletes. Los grupos navieros que operaban antes debían su prosperidad económica a una política de integraciones verticales minería-transporte de mineral (Martínez de las Rivas, Sota y Aznar) como mecanismo de defensa frente a la marina mercante extranjera, que controlaba la mayoría del tráfico de mineral y combustible por el puerto de Bilbao ${ }^{119}$, o a su dedicación al cabotaje o al comercio con América (Martínez Rodas). A partir de 1901, y con el comienzo de la crisis de los fletes, hay un doble proceso en lo que concierne a la creación de compañías navieras: por una parte, una estrategia de concentraciones horizontales practicadas por los grupos creados en la etapa anterior, que se plasma en la creación de nuevas compañías con elevado capital medio; por otra, la creación hasta 1909 de pequeñas compañías vinculadas al comercio de cabotaje, navegación que sí estaba protegida, de carácter colectivo o comanditario y con un escaso capital social.

- Una política de creación de compañías de seguros por los grupos navieros más poderosos (Sota y Aznar, Martínez Rodas) con las cuales, además de explotar el negocio de los seguros, aseguran su propia flota.

- Dentro de esa misma estrategia se sitúa la creación de astilleros por navieros interesados en construir su propia flota, además de abastecer a otros posibles demandantes.

- Una política de sustitución de importaciones por parte de los grupos siderúrgicos, que les lleva a intervenir en la creación de la mayoría de las empresas metalúrgicas a partir de la promulgación del Arancel proteccionista de 1891. Sólo así terminaron los problemas de superproducción de una siderurgia originados al perder los mercados exteriores para el lingote Bessemer.

- A partir de 1901 , y por parte de grupos empresariales centrados anteriormente en otros sectores, fundamentalmente el siderometalúrgico, hay una fuerte inversión en compañías eléctricas. Estos mismos grupos serán los artífices del Banco de Vizcaya, el banco eléctrico por excelencia.

11. Fernández de Pinedo (1985 a), pp. 21-22. 
- Una política, por parte de la gran mayoría de los inversores mineros, de reinvertir los beneficios en el propio sector, especialmente en minería fuera de Vizcaya.

Por lo que respecta a la contribución de la minería al desarrollo industrial de Vizcaya, creemos que la teoría tradicional debe ser cuestionada por varias razones:

- De nuestro listado de inversores en minería se deduce que hubo muchos más que ese «reducido grupo de empresarios y compañías» que controlan «la mayor parte de la producción, de la exportación y de los beneficios del sector» ${ }^{120}$. Teniendo en cuenta que nuestro listado procede de compañías de gran tamaño o, cuando menos, mediano, se confirma la tesis de Escudero para la minería de que «más de un tercio de los beneficios se desparramó entre las clases medias» ${ }^{121}$.

- La presencia de inversores de origen minero en los demás sectores fue importante en algunos y más modesta en otros, pero de ningún modo fue decisiva para el desarrollo industrial de Vizcaya. En la primera etapa, 1886-1900, los porcentajes oscilan entre el 12 y el 25 por 100 , con una media general del 20 por 100 . Pero, además, esa presencia no significó reinversión en su totalidad: en muchos casos fueron navieros o siderometalúrgicos los que invirtieron en minería. Parece, pues, que las corrientes de reinversión no tuvieron ese sentido univoco - minería-restantes sectores- que la teoría tradicional ha postulado. En la segunda etapa, 1901-1913, los porcentajes de inversores mineros siguen oscilando en torno a ese 20 por 100 . La afirmación de que a partir de 1901 los beneficios de la minería se reinvirtieron masivamente en nuevos sectores también tiene que ser matizada: de los 250 inversores de nuestra muestra que intervinieron en el primer período y que vuelven a invertir en la etapa 1901-1913, sólo el 31,2 por 100 fueron inversores mineros en la primera etapa. Luego hubo casi un 70 por 100 de reinversores cuyos beneficios no procedieron de la exportación de mineral. Pero, además, la mayoría de las reinversiones no se dirigieron hacia la industria.

- Donde fueron en mayor medida los beneficios mineros fue al mismo sector. De ese 31,2 por 100 de reinversores mineros, el 80,7 por 100 invirtió de nuevo en minería, la cual se encontró mayoritariamente, como ya hemos dicho, fuera de Vizcaya.

En resumen, hubo más inversores y más fuentes de capital que las procedentes del sector minero y, por tanto, la contribución del mismo no explica

120 González Portilla (1981), vol. I, p. 68.

121 Escudero (1985), en prensa. 
por sí sola la industrialización de Vizcaya. Las investigaciones más recientes que han revisado la teoría tradicional y los resultados que se desprenden de nuestro estudio apuntan hacia una teoría de la industrialización vizcaína mucho más compleja que la simplista teoría tradicional.

\section{APENDICE}

Grupo Ibarra-Zubiría Vilallonga, 1886-1900. Diversiticación de inversiones

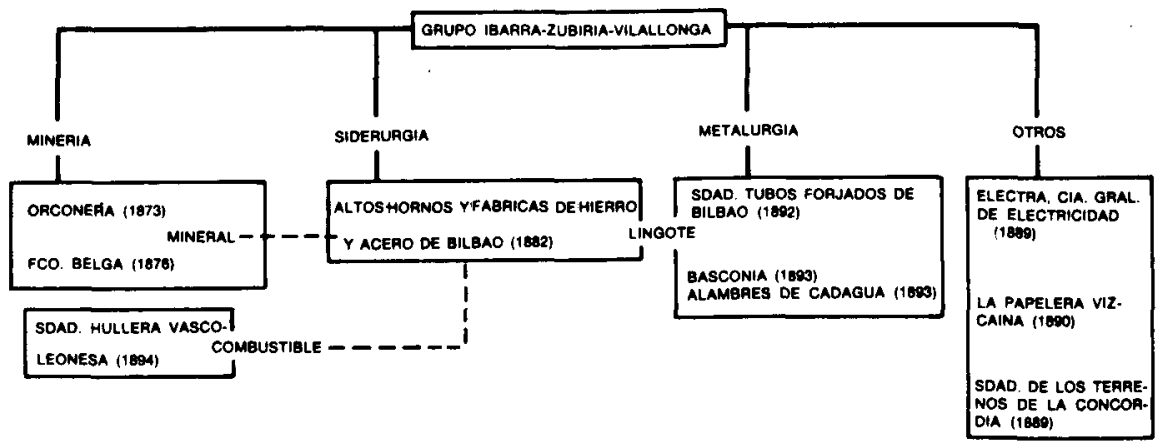

Grupo Chávarri-Salazar, 1886-1900. Diversificación de inversiones

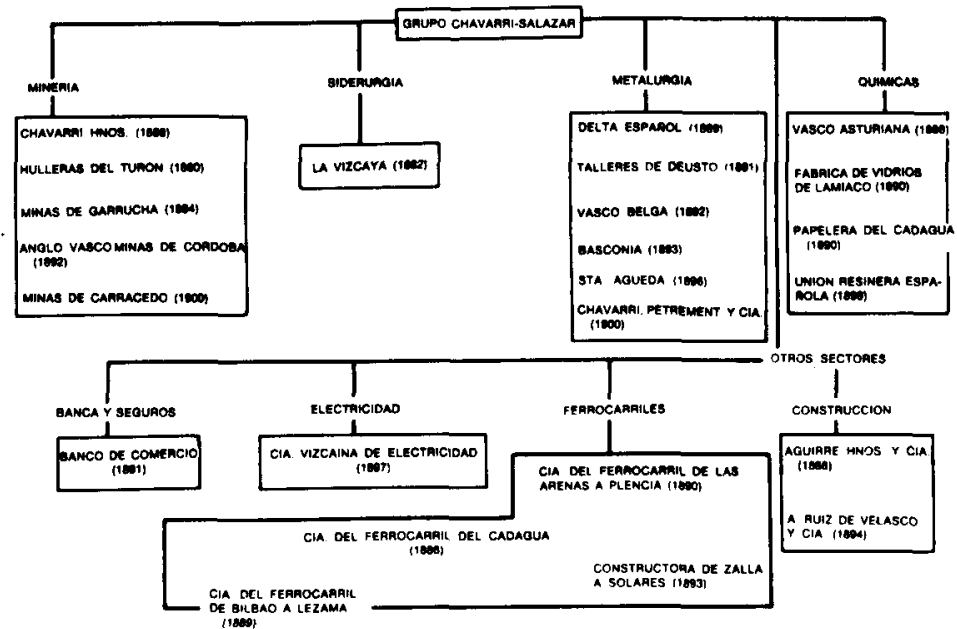




\section{Grupos Echevarría y Picavea. 1901-1913. Su conexión en el sector eléctrico}

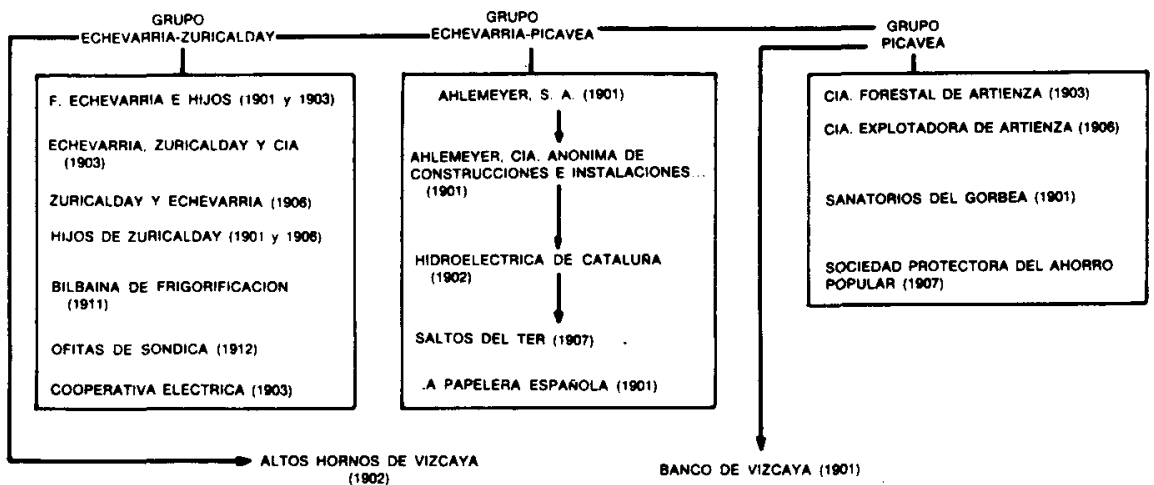

El crédito de la Unión Minera. Un banco de y para la mineria

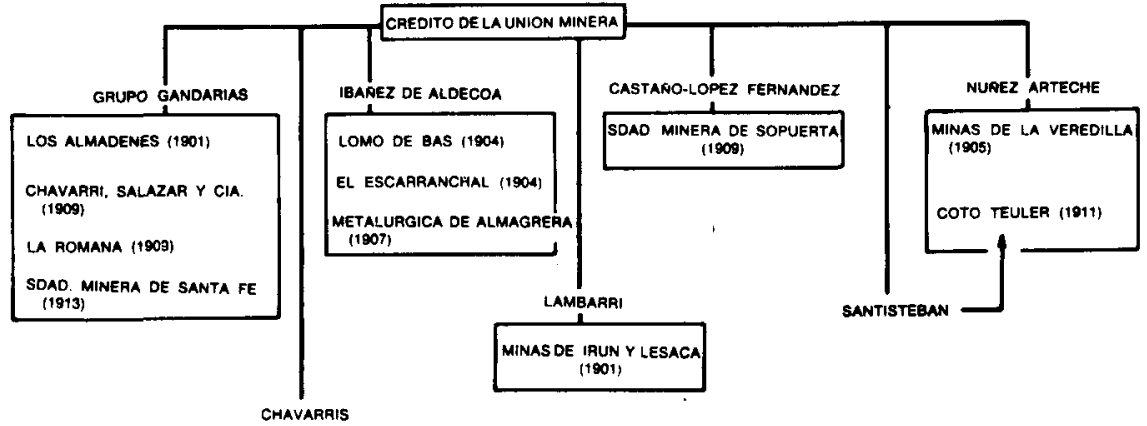


Grupos empresariales y creación de bancos. El caso del Banco Naviero Minero $y$ el Banco Vascongado

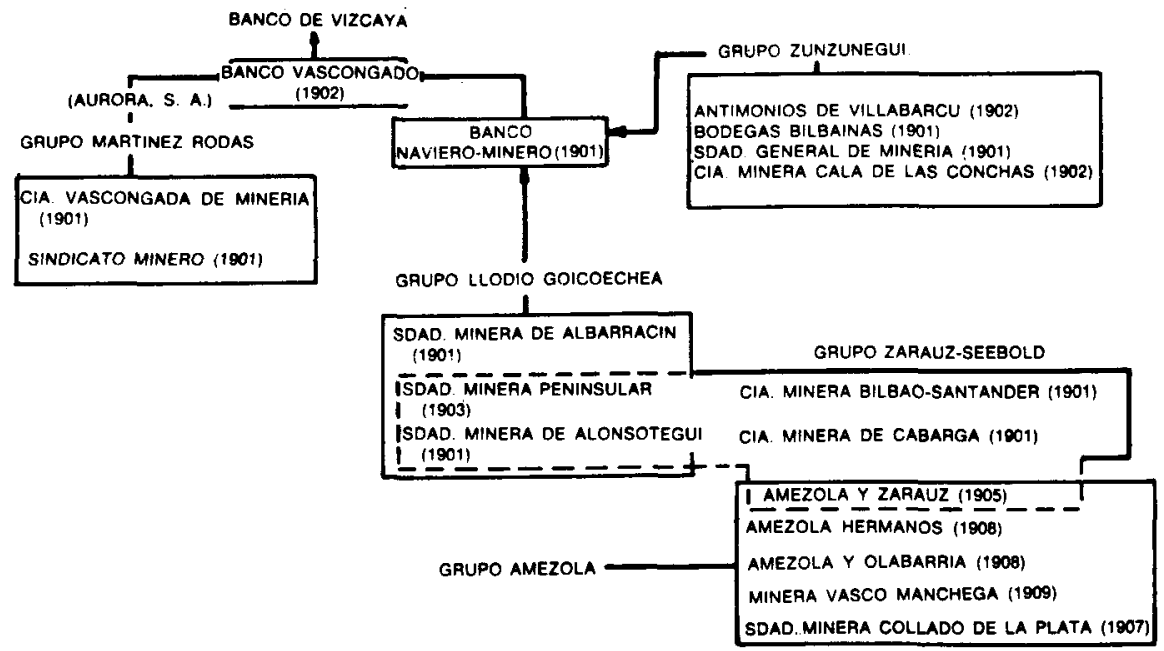

Grupo Sota y Aznar, 1886-1913. Configuración de una integración vertical

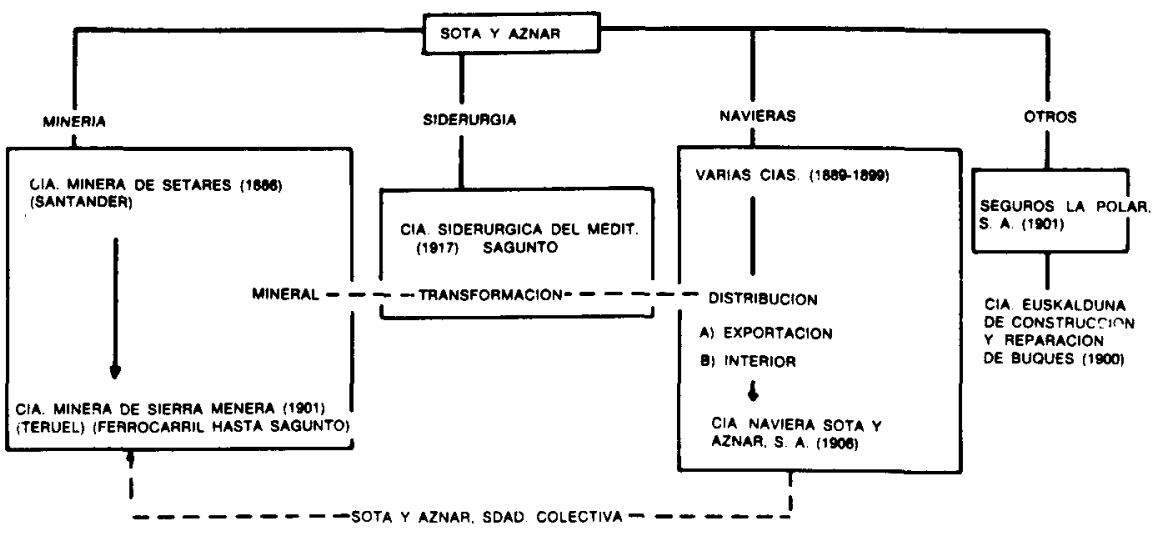




\section{La creación de Saltos del Ter, S. A.: un ejemplo de la profundización de las relaciones entre las diferentes burguesias}

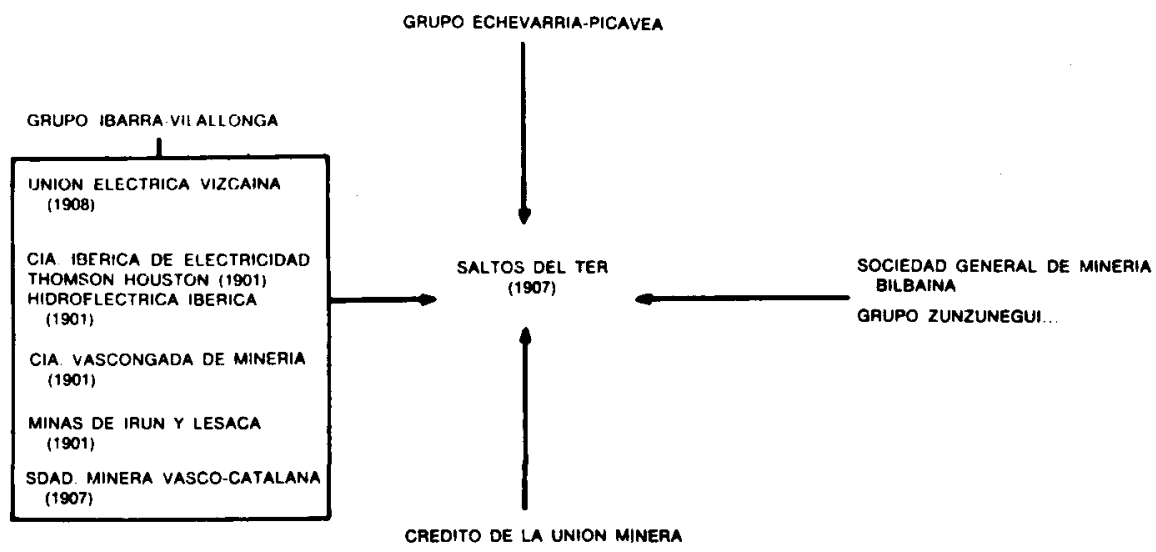

\section{Grupo Chávarri-Salazar, 1901-1913. Diversificación de relaciones interpresariales}

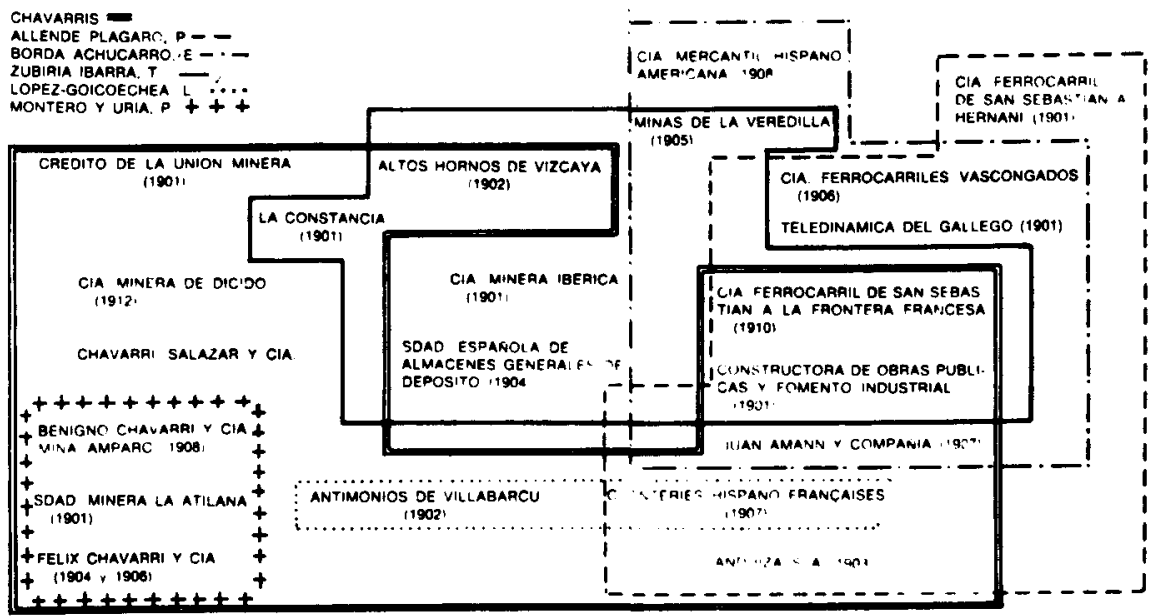




\section{BIBLIOGRAFIA}

BAnco De Bilbao (1957): Un siglo en la vida del Banco de Bilbao, Madrid.

Carreras i Odriozola, Albert (1985): *La producción industrial catalana y vasca, 18441935. Elementos para una comparación», en Industrialización y Nacionalismo. Análisis Comparativos, Barcelona, pp. 197-210.

Escudero, Antonio (1985): «Minería e Industrialización en Vizcaya. Objeciones a una teoría tradicional», en I Encuentro de Historia Económica Regional: El proceso de Industrialización en la cornisa cantábrica (Estado de la cuestion), Vitoria, en prensa.

- (1986): Expansión y decadencia de la minería vasca (1876-1936), tesis doctoral, Vitoria, 3 vols.

Fernández de Pinedo, Emiliano (1983): «Nacimiento y consolidación de la moderna siderurgia vasca (1849-1913): el caso de Vizcayaw, Información Comercial Española, 598, pp. 9-19.

- (1985 a): «Las dudosas bases económicas del nacionalismo vasco en el último cuarto del siglo XIX», Cuadernos de Alzate, 2, pp. 18-25.

- (1985 b): «Factores técnicos y económicos en el origen de la moderna siderurgia y flota vizcaína (1880-1899)w, en I Encuentro de Historia Económica Regional: El proceso de Industrialización en la cornisa cantábrica (Estado de la cuestión), Vitoria, en prensa.

Gonzílez Portilla, Manuel (1981): La formación de la sociedad capitalista en el País Vasco (1876-1913), San Sebastián, 2 vols.

HARrison, Joseph (1983): «La industria pesada, el Estado y el desarrollo económico en el País Vasco, 1876-1936*, Información Comercial Española, 598, pp. 21.32.

LAzúRTEGUI, Julio (1907): Alusión al discurso inaugural y teoría de la expansión económica de Vizcaya, ocasionada por la explotación de sus yacimientos ferruginosos de de 1876 a 1906, Bilbao.

Lequerica, José Félix (1956): La actividad económica de Vizcaya en la vida nacional, Madrid.

Maluquer de Motes, Jordi (1985): «Cataluña y el País Vasco en la industria eléctrica española, 1901-1935 , en Industrialización y Nacionalismo. Análisis Comparativos, Barcelona, pp. 239.252 .

MAlUQUER DE MOTES, Jordi (1987): «De la crisis colonial a la guerra europea: veinte años de economía española», en La economía española en el siglo XX. Una perspectiva bistórica, Barcelona.

NADAL, Jordi (1986): «La debilidad de la industria química española en el siglo xIx. Un problema de demandaw, Moneda y Crédito, 176, pp. 33-70.

SUdRÍ I Triay, Carles (1985): *Formas de industrialización y desarrollo bancario en Cataluña y Euskadi (1840-1936)*, en Industrialización y Nacionalismo. Análisis Comparativos, Barcelona, pp. 253-266.

Tortella Casares, Gabriel (1983): *La primera gran empresa química española: la Sociedad Española de la Dinamita (1872-1896)», en Historia Económica y Pensamiento Social. Estudios en bomenaje a Diego Mateo del Peral, Madrid, pp. 431-454.

Tuñón de Lara, Manuel (1983): Prólogo al trabajo de J. L. Garcfa Delgado, «La economía española entre 1914 y 1923», en Historia de España, dirigida por M. Tuñón de Lara, vol. VIII: Revolución burguesa, oligarquía y constitucionalismo (18341923), Barcelona, 3." ed., pp. 409-414.

Valdaliso Gigo, Jesús M:" (1986): Creación de Sociedades e Industrialización en Vizcaya (1886-1975), tesis de licenciatura, Vitoria.

VÁzquez Garcfa, Juan A. (1980): «Creación de Sociedades e inversión en Asturias (1886-1973). El auge de fin de siglo*, Investigaciones Económicas, 12, pp. 165-185.

Ybarra y Berge, Javier (1947): Politica Nacional en Vizcaya. De la Restauración a la República, Madrid. 